\title{
La reapertura del concurso de personas jurídicas y su finalidad liquidatoria: estudio de su régimen legal
}

\author{
Enrique Gadea Soler \\ Profesor Titular de Derecho Mercantil \\ Universidad de Deusto
}

Recibido: 18.10 .2010

Aceptado: 01.12 .2010

Resumen: La Ley Concursal contiene dos modelos de reapertura, uno para las personas naturales y otro para las personas jurídicas, sometidos a presupuestos no coincidentes. En las siguientes páginas pretendemos realizar un estudio general de la reapertura del concurso de personas jurídicas, con el objeto de dar respuesta a los problemas derivados de las lagunas e imprecisiones contenidas en el texto legal.

Palabras clave: Reapertura del concurso, personas jurídicas, extinción y liquidación.

Abstract: The Insolvency Act has two reopening models, one for natural persons and another for legal persons, which are subject to non-coincident rules of procedure. In the following pages, we will offer an insight into the reopening of bankruptcy proceedings for natural persons to respond to the problems resulting from omissions and inaccuracies contained in legal texts.

Key words: reopening of bankruptcy proceedings, legal persons, extinction and liquidation.

Sumario: I. LA CONFIGURACIÓN DE LA REAPERTURA EN LA LEY CONCURSAL.-II. PRESUPUESTOS DE LA REAPERTURA DEL CONCURSO DE PERSONAS JURÍDICAS. 1. Presupuesto objetivo. 2. Presupuesto temporal. 3. Presupuesto subjetivo. 3.1. El Juez competente para conocer de la reapertura. 3.2. Partes legitimadas para solicitarla. 4. Presupuesto formal. 4.1. Forma y contenido de la resolución judicial. 4.2. Publicidad.-III. EFECTOS DE LA REAPERTURA DEL CONCURSO DE PERSONAS JURÍDICAS.-IV. OPERACIONES DE LA REAPERTURA: EL NUEVO INFORME DE LA ADMINISTRACIÓN CONCURSAL. 1. Contenido y plazo de presentación del "nuevo informe". 2. Actualización del inventario. 3. Actualización de la lista de acreedores. 4. Publicidad y posible impugnación del inventario y de la lista de acreedores.- $\mathrm{V}$. LA SOLUCIÓN LIQUIDATORIA PARA EL CONCURSO REABIERTO.

\section{LA CONFIGURACIÓN DE LA REAPERTURA EN LA LEY CON- CURSAL}

El fundamento de la reapertura se encuentra en la responsabilidad patrimonial universal del deudor prevista en el artículo 1911 CC, en cuya virtud 
el deudor cuyo concurso fue cerrado por insuficiencia de bienes y derechos para hacer frente al pago íntegro de todas sus deudas (artículo 176.1.4. ${ }^{\circ} \mathrm{LC}$ ), continúa respondiendo ante sus acreedores con todos sus bienes presentes y futuros. Y ello es así porque la conclusión formal del concurso por inexistencia o insuficiencia de bienes y derechos no produce efectos extintivos de los créditos impagados total o parcialmente ya que, según el artículo 178.2 LC, "en los casos de conclusión del concurso por inexistencia de bienes o derechos, el deudor quedará responsable del pago de los créditos restantes" 1 .

La opción de política-legislativa anteriormente referida trae como consecuencia que clausurado el concurso por inexistencia o insuficiencia de bienes o derechos para satisfacer todos los créditos reconocidos, será posible reabrirlo (bajo ciertas condiciones) cuando el patrimonio del deudor experimentara un incremento en su contenido que permitiera reemprender el procedimiento clausurado ${ }^{2}$. Es, por tanto, el fracaso, total o parcial, del procedimiento concursal anterior, unido a la aparición o detección de activo sobrevenido del deudor o de terceros responsables del pago, la única causa a la que la LC vincula la reapertura del concurso.

Al regular los efectos de la conclusión del concurso sobre el deudor, el artículo 178.1 LC prevé que: "en todos los casos de conclusión del concurso, cesarán las limitaciones de las facultades de administración y disposición del deudor subsistentes, salvo las que se contengan en la sentencia firme de calificación". La razón de la cesación de las limitaciones del ejercicio de las facultades de administrar y disponer se encuentra en que, concluido el concurso, carecen de razón de ser. En efecto, concluido el concurso, el deudor podrá ejercer libremente las facultades de administración y disposición de sus bienes (actuales y futuros) dado que, con la conclusión, desaparecen los órganos encargados de ejercer tales facultades (si el deudor estaba suspendido) o de controlar su ejercicio (si estaba meramente intervenido), así como los intereses del concurso, a cuya satisfacción debía atenderse en el ejercicio de las mencionadas facultades de administrar y de disponer (artículo 43). Por todo ello, el deudor podrá realizar actos de administración y de disposición, y de cualquier otro tipo, tanto en el ámbito sustantivo como en el procesal, sin requerir ningún tipo de autorización y sin tener que atender a ningún interés ajeno ${ }^{3}$. No obstante, esa regla general presenta dos excepciones:

1 ALONSO ESPINOSA F. J., "Comentario a los artículos 179 y 180 de la LC”, en AA.VV., Comentarios a la Legislación Concursal, dirigidos por PULGAR EZQUERRA, ALONSO UREBA, ALONSO LEDESMA Y ALCOVER GARAU, T. II, Dykinson, Madrid, 2004, pág. 1492.

2 YANES, P., "Comentario al artículo 179 de la LC", en AA. VV., Comentarios a la Legislación Concursal, dirigidos por SÁNCHEZ CALERO Y GUILARTE GUTIÉRREZ, T. III, Lex Nova, Valladolid, 2004, pág. 2950.

${ }^{3}$ BELTRÁN Y MARTÍNEZ FLOREZ, BELTRÁN, E. Y MARTINEZ FLOREZ, A., "Comentario del artículo 178", en ROJ.O, A./ BELTRÁN, E. (Dir.), Comentario de la Ley Concursal, Vol. Il, Civitas, Madrid,, 2004, pág. 2649. 
La primera, que se encuentra prevista en el propio artículo 178.1 in fine, deja a salvo del cese de las limitaciones de las facultades de administración y disposición "las que se contengan en la sentencia firme de calificación". La sentencia que califique el concurso como culpable puede inhabilitar para administrar los bienes ajenos y para representar o administrar a cualquier persona (artículo 172.2.2. ${ }^{\circ} \mathrm{LC}$ ); inhabilitación que se extiende al ejercicio de la actividad empresarial individualmente o por medio de una sociedad (artículo 13.2. ${ }^{\circ}$ C.Com). En consecuencia, el deudor inhabilitado podrá administrar y disponer de los bienes propios, aunque no podrá, en ningún caso, ejercer actividad empresarial mientras dure la inhabilitación.

La segunda no se recoge en el precepto, pero se deriva de la propia naturaleza de las cosas. Según el artículo 178.3 LC, "en los casos de conclusión del concurso por inexistencia de bienes y derechos del deudor persona jurídica, la resolución judicial que la declare acordará (es un deber) su extinción y dispondrá el cierre de su hoja de inscripción en los registros públicos que corresponda, a cuyo efecto se expedirá mandamiento conteniendo testimonio de la resolución firme". En realidad, más que el cierre de la hoja registral, la LC quiere decir la cancelación registral de oficio de la sociedad ${ }^{4}$. En cualquier caso, como la conclusión conlleva la extinción de la persona jurídica, no tiene sentido hablar de cesación de las limitaciones al ejercicio de las facultades patrimoniales 5 .

Desde otro plano, el artículo 178.2 LC, en consonancia con la responsabilidad patrimonial del deudor del artículo $1911 \mathrm{CC}$, establece que: "en los casos de conclusión del concurso por inexistencia de bienes y derechos, el deudor quedará responsable del pago de los créditos restantes. Los acreedores podrán iniciar ejecuciones singulares en tanto no se acuerde la reapertura del concurso o no se declare nuevo concurso". No obstante, como en el supuesto expuesto anteriormente, este planteamiento es aplicable a las personas naturales, pero no para las personas jurídicas, en cuyo caso no puede hablarse de continuación de la responsabilidad del deudor y de la recuperación de las acciones individuales de los acreedores porque, en estos supuestos, la conclusión del procedimiento por la causa referida produce la extinción de la persona jurídica (artículo 178.3 LC), que, por ese motivo, dejará de responder de las deudas no satisfechas, sin perjuicio de una eventual reapertura del concurso (artículo 179.2 LC) ${ }^{6}$.

${ }^{4}$ Como ha señalado PULGAR EZQUERRA, J. (La declaración del concurso de acreedores, La Ley/Ramón y Cajal, Madrid, 2005, pág. 166), en el supuesto que nos ocupa lo que realmente se producirá no es un mero cierre que constituye una medida coercitiva con la que se persigue garantizar la efectividad del cumplimiento por el sujeto inscrito de la obligación de dar publicidad a sus cuentas anuales (artículos 221.1 LSA y 378 RRM), sino una cancelación registral de oficio de la sociedad inscrita.

${ }^{5}$ BELTRÁNY MARTÍNEZ FLOREZ, “Comentario del artículo 178...”, op. cit., pág. 2649.

${ }^{6}$ BELTRÁN Y MARTÍNEZ FLOREZ, “Comentario del artículo 178...”, op. cit., pág. 2662 . 
Es cierto que la LC sin distinción entre uno y otro caso (personas naturales y jurídicas), sitúa el supuesto descrito entre las causas de conclusión del concurso (artículo 176.1.4. ${ }^{\circ}$ ). Sin embargo, así como los efectos de recuperación de facultades del deudor y de posibilidad de inicio de ejecuciones individuales por los acreedores, nos conducen a la concepción de la reapertura como una nueva declaración de concurso, parece que supeditada a la concurrencia de alguno de los supuestos del artículo 2 LC y en la que no encontramos razón para no admitir las distintas soluciones al procedimiento, incluida la concordataria; el efecto extintivo previsto para las personas jurídicas obliga, si tras la conclusión del concurso aparecen nuevos bienes, a reabrir necesariamente el mismo concurso, quedando limitada, además, la reapertura a la fase de liquidación (artículo 179.2) . $^{7}$.

De todo ello y a modo de conclusión, creemos que puede deducirse que la LC no contiene un modelo de reapertura sino dos modelos distintos, uno para las personas naturales y otro para las personas jurídicas, sometidos a presupuestos no coincidentes ${ }^{8}$. En las siguientes páginas pretendemos realizar un estudio general de la problemática de la reapertura del concurso de personas jurídicas.

\section{PRESUPUESTOS DE LA REAPERTURA}

\section{Presupuesto objetivo}

El presupuesto objetivo de la reapertura tiene diferente relevancia según el deudor sea persona física o persona jurídica. En el supuesto que nos ocupa la conclusión del concurso por inexistencia de bienes y derechos conlleva la extinción de la persona jurídica ${ }^{9}$, por lo que no tiene sentido hablar de recuperación de las facultades patrimoniales de los administradores o liquidadores societarios o de los administraciones concursales, dado que todos

${ }^{7}$ ALONSO ESPINOSA., “Comentario a los artículos 179 y 180...”, op. cit., pág. 1498.

${ }^{8}$ PULGAR EZQUERRA, La declaración..., op. cit., pág. 785.

${ }^{9}$ Nos resulta difícil imaginar un caso de conclusión de un concurso de una persona jurídica por "insuficiencia" de masa activa. Es cierto que parece lógico que el concurso se ciere si los bienes existentes no son suficientes para cubrir los gastos del procedimiento o, incluso, cuando su valor sólo alcance para cubrir esos gastos pero no el resto de los créditos; sin embargo, si la conclusión del concurso por esta causa conlleva el efecto general previsto en el artículo 178.3 LC, nos encontraríamos con la extinción de una persona jurídica, que, en mayor o menor medida, tiene patrimonio y con unos acreedores que carecen de acciones para reclamar, salvo que se produzca la reapertura. Volveremos sobre esta cuestión al abordar el tema de la actualización del inventario. De la reducción de gastos del concurso se ha ocupado recientemente el RDL 3/2009, que ha previsto para ello: La gratuidad de las inserciones obligatorias en el $B O E$ (artículo $6 \mathrm{RDL}$ ) y la limitación del arancel de la administración concursal (artículo 7 RDL). 
ellos han cesado en sus cargos (artículos 145 y 181 LC). El efecto extintivo aludido, y la correspondiente cancelación registral de oficio en virtud de la resolución judicial que acuerde la conclusión del concurso por inexistencia de bienes y derechos, no permite hablar tampoco de la recuperación de las acciones individuales de los acreedores ni de la continuación de la responsabilidad del deudor, que, por la extinción societaria, dejará de responder de las deudas no satisfechas. Este efecto determina, en definitiva, que tras la conclusión del concurso no pueda reemprenderse una nueva actividad que termine en nueva insolvencia. En este contexto, para los supuestos de aparición de activo sobrevenido, el artículo 179.2 LC arbitra una solución en protección, dadas las circunstancias, de los acreedores insatisfechos, que no es otra que la reapertura del mismo concurso existente con anterioridad, aunque limitada a la fase de liquidación de los bienes y derechos aparecidos después de la conclusión.

De ese modo, la LC, incluso para las sociedades capitalistas (anónimas y limitadas), adopta para el caso que nos ocupa una solución propia que excepciona la aplicación del artículo 123 LSRL (artículo 248 RRM) ${ }^{10}$, que en el supuesto de aparición de activos sobrevenidos después cancelados los asientos relativos a la sociedad, la considera extinguida con la cancelación y establece un régimen de responsabilidad solidaria de los antiguos socios en relación con el pasivo insatisfecho limitada a lo percibido como cuota de liquidación ("Los antiguos socios responderán solidariamente de las deudas sociales no satisfechas hasta el limite de lo que hubieran percibido como cuota de liquidación, sin perjuicio de la responsabilidad de los liquidadores en caso de dolo o culpa": artículo 123.2 LSRL).

Esta solución propia de la LC, y dirigida a la protección de los acreedores insatisfechos, solo contempla la reapertura con efectos liquidatorios, pero en ningún caso se refiere a la posibilidad de satisfacción a los acreedores por vía concordataria ni a la posible reactivación de la sociedad con efectos duraderos, ni siquiera bajo el supuesto, ciertamente no muy frecuente en la práctica, de la subsistencia de activo sobrante después de haber pagado todos los acreedores (imaginemos una operación de recalificación urbanística que ha convertido terrenos sin valor en terrenos cuyo valor permite cubrir el pasivo y que quede un importante remanente).

\section{Presupuesto temporal}

La LC no configura la inexistencia o el agotamiento de la masa activa sin íntegra satisfacción de los acreedores, como el Anteproyecto de Ley Concursal de 1983 y Propuesta de Anteproyecto de Anteproyecto de Ley Concursal

${ }^{10}$ Artículo 123 que, como es sabido, sigue el modelo diseñado por el artículo 2456 del Códice Civile italiano de 1942. 
de 1995, como causa de suspensión del concurso, sino como causa de conclusión (artículo 176.1.4. ${ }^{\circ}$ ). La norma, siguiendo lo previsto en el artículo 121 de la Legge fallimentare italiana de 1942, señala que el plazo para la reapertura es de cinco años, se entiende que a contar desde la firmeza del auto de conclusión. En efecto, el artículo 179.1 LC establece que: "la declaración de concurso de deudor persona natural dentro de los cinco años siguientes a la conclusión de otro anterior por inexistencia de bienes o derechos tendrá la consideración de reapertura de éste". Sin embargo, la referencia que hace la norma a la vigencia del plazo quinquenal no es aplicable a la reapertura del concurso de personas jurídicas que hubiera concluido por inexistencia de bienes y derechos, para la que, en realidad, no existe presupuesto temporal. Ello se justifica por los efectos singulares de la conclusión del concurso de personas jurídicas en la medida que la resolución judicial que la declare acordará su extinción y dispondrá la cancelación registral de oficio de la sociedad (artículo 178.3 LC). Este efecto determina que, tras la conclusión del concurso, no pueda reemprenderse una nueva actividad que termine en nueva insolvencia, y que sólo pueda plantearse la hipótesis de descubrimiento de bienes no liquidados antes de la conclusión o de aparición de bienes de terceros responsables ${ }^{11}$, en cuyo caso procederá la reapertura del concurso, que se limitará a la fase de liquidación (artículo 179.2 LC) ${ }^{12}$.

\section{Presupuesto subjetivo}

Tradicionalmente, con la expresión "presupuesto subjetivo", en el ámbito concursal, se ha pretendido poner de relieve cuáles eran las personas o entidades a las que podía aplicárseles uno u otro procedimiento en caso de insolvencia. Como es sabido, hasta la aprobación de la LC en 2003 se regulaban distintos procedimientos para el tratamiento de esta situación. En cambio, la nueva regulación parte del principio de unidad de disciplina, con lo que unifica el tratamiento de los deudores comerciantes y no comerciantes. Es por ello que, bajo este epígrafe, vamos a tratar dos cuestiones que nada tienen que ver con la delimitación del concepto de comerciarte (empresario,

${ }^{11}$ Entre otros, socios colectivos o administradores o liquidadores societarios afectados por la sentencia de calificación. Sobre esta cuestión, ÁLCALA DÍAZ, M.. a A., "Comentario al artículo 176 de la LC", en AA. VV., Comentarios a la Legislación Concursal, dirigidos por PULGAR EZQUERRA, ALONSO UREBA, ALONSO LEDESMA Y ALCOVER GARAU, T. II, Dykinson, Madrid, 2004, págs. 1458- 1459.

${ }^{12}$ YANES, "Comentario al artículo 179...", op. cit., págs. 2953 y 2954. Es por ello por lo que ALONSO ESPINOSA (en "Comentario a los artículos 179 y $180 \ldots$.., op. cit., pág. 1498), ha señalado que la reapertura actúa aquí como técnica complementaria de reintegración de la masa activa del concurso para su consiguiente liquidación ordenada entre los acreedores insatisfechos. En el mismo sentido, PULGAR EZQUERRA, La declaración..., op. cit., pág. 167. 
en la denominación más moderna), como son el Juez competente para conocer de la reapertura y las partes legitimadas para solicitarla.

\subsection{El Juez competente para conocer de la reapertura}

Tratándose de deudor persona jurídica, la LC atribuye expresamente la competencia para conocer de la reapertura del concurso al mismo Juzgado que conoció de éste (artículo 179.2). La razón se recoge en la Exposición de Motivos de la Ley, IX, y, posteriormente, en el texto articulado (artículo 178.3 LC), dado que si la conclusión del concurso por inexistencia de activos patrimoniales lleva consigo la extinción de la persona jurídica concursada y el cierre de su hoja de inscripción en los registros públicos, no cabe imaginar la modificación de las circunstancias consideradas inicialmente para la determinación de la competencia territorial del órgano que abrió el primer concurso $^{13}$.

\subsection{Partes legitimadas para solicitarla}

No contiene la LC, tal como sería deseable, una previsión especifica sobre quiénes están legitimados para solicitar la reapertura. Cuando el concurso se hubiese dirigido frente a un deudor persona jurídica, como la resolución judicial del concurso por inexistencia de bienes y derechos ha decretado su extinción, es dudoso que tengan capacidad para solicitar la reapertura los administradores (o liquidadores) societarios (legitimados para solicitar la declaración del concurso, según el artículo 3.1 II LC) y concursales, que han sido cesados en sus cargos. Lo que no ofrece duda es que están legitimados los acreedores no satisfechos que fueron parte en el procedimiento concluido, y también los socios, miembros o integrantes que sean personalmente responsables, conforme a la legislación vigente, de las deudas de aquélla (artículo 3.3 LC). En el ámbito de las sociedades mercantiles, la norma comprende, entre otros, a los socios colectivos de una sociedad colectiva, comanditaria simple y comanditaria por acciones (artículos 127, 148 y 151 del C.Com), a los socios comanditarios en caso de inclusión de su nombre en la razón social de la entidad (artículo 147 C.Com), a los socios de una agrupación de interés económico (artículo 5 de la Ley 12/1991, de 29 de abril, de agrupaciones de interés económico) y al socio único de una sociedad unipersonal sin que esta circunstancia se haya hecho constar en el RM transcurri-

${ }^{13}$ Así, YANES, “Comentario al artículo 179...”, op cit., pág. 2955 y GONZÁLEZ OLLEROS, J., "Comentario al artículo 179 LC", en Derecho Concursal Práctico (Comentarios a la Nueva Ley Concursal), Coordinado por FERNÁNDEZ-BALLESTEROS, La Ley/Iurgium, Madrid, 2004, pág. 809. 
dos seis meses desde la adquisición (artículo 129 LSRL) ${ }^{14}$. Su interés para solicitar la reapertura es claro si pensamos en una sociedad que tiene deudas pendientes, por no haber podido ser satisfechas con el patrimonio social ni por ellos. En ese contexto, la reapertura por aparición de activo sobrevenido les podrá liberar de su responsabilidad subsidiaria por todas o, al menos, por parte de las deudas sociales.

\section{Presupuesto formal}

\subsection{Forma y contenido de la resolución judicial}

Como es sabido, para el Derecho es irrelevante la situación económica de insolvencia., sólo existe concurso, voluntario o necesario, cuando es declarado por resolución judicial, que reviste la forma de auto. Pues bien, de igual modo, la declaración de reapertura de un concurso ha de tener lugar mediante resolución judicial (también del Juez de lo mercantil, que es el competente en materia concursal: artículo $8 \mathrm{LC}$ ) que debe revestir la forma de auto (artículo 21 LC). La LC no delimita el contenido de este auto, aunque, en el caso de las personas jurídicas, habida cuenta de que la reapertura tiene un objeto más limitado (fundamentalmente, la continuación de las operaciones de liquidación de la masa activa), el contenido del auto será más reducido, aunque, en todo caso, deberá contener los pronunciamientos relativos al nombramiento y a las facultades de la administración concursal y al régimen de publicidad de dicho auto.

\subsection{Publicidad}

En cuanto al régimen de publicidad, la LC señala que a la reapertura del concurso del deudor persona jurídica se le dará la publicidad prevista en los artículos 23 y 24 LC (artículo 179.2 LC in fine), con lo que el legislador se ha decantado por regular el sistema de publicidad de la reapertura sobre la base del de la declaración de concurso ${ }^{15}{ }^{16}$. Es por ello que el auto de reaper-

\footnotetext{
${ }^{14}$ RONCERO SANCHEZ, A., "Comentario al artículo 3 de la LC", en AA.VV., Comentarios a la Legislación Concursal, dirigidos por PULGAR EZQUERRA, ALONSO UREBA, ALONSO LEDESMA Y ALCOVER GARAU, T. I, Dykinson, Madrid, 2004, pág. 188.

${ }^{15}$ GUTIÉRREZ GILSANZ, A., "Conclusión y reapertura del concurso", en AA. VV., Aspectos jurídicos del nuevo concurso de acreedores", Coord. MARAITA LAVIÑA, ICAM, 2004, pág. 326.

${ }^{16}$ Repárese que esta materia ha sido modificada por el RDL 4/2009. Como ha señalado sobre la reforma COLINO MEDIAVILLA, J. L., (en "La publicidad del concurso en virtud del Real Decreto-Ley 3/2009”, RDCP, Núm. 11, 2009, págs. 123 y ss.), la aplicación de la LC había puesto de manifiesto que, conforme a su regulación, la publicidad del concurso era cara, sobre todo por la utilización de periódicos privados, y menos ágil de lo deseable, en particular por el insuficiente aprovechamiento de la tecnología disponible. La opción por la
} 
tura del concurso debe notificarse a las partes que hubiesen comparecido. Si no comparece el deudor, la publicación prevista en el artículo 23 LC producirá, respecto de él, los efectos de notificación del auto (artículo 21.5 LC). Junto a la notificación a las partes, la LC impone a la administración concursal la obligación de realizar una comunicación individualizada a cada uno de los acreedores cuya identidad y domicilio conste en el concurso (artículo 21.4), informándoles de la declaración de éste y del deber de comunicar sus créditos en la forma prevista en el articulo $85 \mathrm{LC}$, si bien en el caso de la reapertura este deber -carga- no debe recaer sobre los acreedores cuyo crédito ya ha sido reconocido. Esta comunicación, como las restantes del concurso y de la reapertura del concurso, se realizará preferentemente por medios telemáticos, informáticos y electrónicos, en la forma que reglamentariamente se determine (artículo 23.1 LC).

Respecto al régimen de publicidad en sentido estricto, la LC regula un sistema de publicidad general. En efecto, con carácter necesario, el Juez debe acordar la publicación, con la mayor urgencia y de forma gratuita, del extracto de la declaración de reapertura del concurso en el Boletín Oficial del Estado (artículo 23.1. II LC). Además, también puede acordar, de oficio o a instancia del interesado, cualquier publicidad complementaria que considere imprescindible para la efectiva difusión de los actos del concurso (artículo 23.2: por ejemplo, en los Diarios Oficiales de las Comunidades Autónomas o de la Provincia). El traslado de los oficios con los edictos se realizará preferentemente por vía telemática desde el Juzgado a los medios de publicidad correspondientes, excepcionalmente, y si ello no fuese posible, los oficios con los edictos serán entregados al procurador del solicitante que se debe encargar de remitirlos de inmediato a los medios de publicidad correspondientes. Si el solicitante del concurso fuese una Administración Pública, que actuase representada y defendida por sus servicios jurídicos, el traslado del oficio debe realizarse directamente por el Juzgado a los medios de publicidad (artículo 23.3 LC).

El auto también será objeto de publicidad registral. En cuanto a la publicidad registral de la persona declarada en concurso, el Registrador mercantil o el encargado del Registro administrativo competente, deberá inscribir la declaración de reapertura de la entidad extinguida y el nombramiento de los administradores concursales (artículo 24.2 y 3 LC).

preferencia en la utilización de medios telemáticos, informáticos y electrónicos, y su carácter gratuito, parece satisfactoria, porque no pueden desaprovecharse las ventajas de inmediatez informativa (información pública y permanente), bajo coste (que permite establecer la gratuidad para el interesado en la información) y rapidez en la tramitación que ofrecen las tecnologías telemáticas, informáticas y electrónicas. Sobre todo, porque tales ventajas pueden obtenerse sin merma de la necesaria seguridad jurídica y sin que padezcan las funciones propias de los distintos tipos de publicidad en el marco del procedimiento concursal. 


\section{EFECTOS DE LA REAPERTURA}

La LC no ofrece una regulación sistemática de los efectos de la reapertura del concurso. Ahora bien, lo cierto es que, a diferencia de la reapertura de un concurso de persona natural, que irá acompañada de los efectos propios del concurso, de la reapertura de concurso de deudor persona jurídica, se derivan efectos más limitados, al tratarse de una entidad extinguida para la que la LC solo contempla la reapertura con efectos liquidatorios, por lo que no tiene sentido hablar de recuperación, en mayor o menor medida y mientras dure el procedimiento, de las facultades patrimoniales de los administradores societarios, ni de la posible reactivación de la sociedad con efectos duraderos. También es discutible, en este supuesto, que con la conclusión del concurso se inicie nuevamente el cómputo del plazo de prescripción (artículo 60.3 LC), al no recuperar los acreedores la posibilidad de ejercitar sus acciones individuales ${ }^{17}$, ni tener posibilidad de reclamación extrajudicial ni de solicitar el reconocimiento de su deuda a un deudor que ya no existe (es decir, al no tener ninguna opción para interrumpir la prescripción de sus acciones atendiendo a alguna de las causas previstas en el artículo 1973 CC). Sin embargo, efecto común, con independencia de la naturaleza de la persona (natural o jurídica) que se vea afectada por la situación de reapertura y de gran trascendencia para el desarrollo del procedimiento, es el nombramiento de los administradores concursales. La LC no contiene una previsión general sobre este particular, aunque la importancia de esta figura se desprende de lo previsto en el artículo 180.1, cuando señala que: "Los textos definitivos del inventario y de la lista de acreedores... habrán de ser actualizados por la administración concursal...". Cuestión distinta son las más amplias o más limitadas funciones del órgano, según se trate de reapertura de concurso de persona natural o de persona jurídica. En la reapertura de concurso de deudor persona jurídica, sus funciones esenciales son la actualización del inventario y de la lista de acreedores, la liquidación de los bienes aparecidos con posterioridad y el pago a los acreedores, en la medida de lo posible, con el producto liquido obtenido con la venta de dichos bienes.

\section{OPERACIONES DE LA REAPERTURA: EL NUEVO INFORME DE LA ADMINISTRACIÓN CONCURSAL}

\section{Contenido y plazo de presentación del "nuevo informe"}

Con independencia de la naturaleza del concursado, la actualización del informe deberá contener, con mayor o menor detalle según los casos, una

17 Como señalan BELTRÁN Y MARTÍNEZ FLOREZ(en "Comentario del artículo 178...”, op. cit., pág. 2665)., “... volverá a correr la prescripción, siempre que la conclusión del concurso... no impida el ejercicio de acciones individuales por los acreedores". 
memoria de las principales decisiones acordadas y de las actuaciones ejecutadas por la administración concursal en el concurso reabierto (artículo 75.1.3. ${ }^{\circ}$ LC) y una exposición motivada de la situación patrimonial del deudor y de cuantos datos y circunstancias pueden ser relevantes para la tramitación del concurso (artículo 75.3 LC) ${ }^{18}$. Al informe han de unirse el inventario y la lista de acreedores actualizados. Respecto al plazo de presentación del informe, el artículo 180.1 LC dispone que: "Los textos definitivos del inventario y de la lista de acreedores formados en el procedimiento anterior habrán de actualizarse por la administración concursal en el plazo de dos meses a partir de la incorporación de aquéllas actuaciones al nuevo concurso". El plazo de dos meses es el fijado por el artículo 74.1 LC para la presentación del primer informe, si bien la diferencia entre uno y otro precepto se encuentra en que el informe inicial debe presentarse en el plazo de dos meses contados a partir de la fecha en que se produzca la aceptación de al menos dos de los tres administradores concursales y el informe actualizado en el plazo de dos meses a contar desde el momento en que queden incorporadas las actuaciones del concurso concluido al concurso reabierto (plazo que debe entenderse que se reduce a un mes cuando la reapertura se trámite por el cauce del procedimiento abreviado: artículo 191.1 LC).

\section{Actualización del inventario}

Tratándose de reapertura de concurso de persona jurídica, como la misma se extingue con la conclusión del concurso por inexistencia de bienes o derechos (artículo 178.3 LC), no cabe pensar en la adquisición de nuevos bienes sino en la aparición o detección de bienes ocultos en un momento posterior, tanto del deudor como de terceros responsables que, por la razón que fuere, quedaron al margen de la liquidación. Igualmente, cabe pensar en que los responsables subsidiarios del pago de las deudas de la sociedad lleguen a mejor fortuna o en bienes incorporados a la masa en virtud del ejercicio de acciones de reintegración. A titulo de ejemplo, y sin ánimo de exhaustividad, cabe señalar que procederá la reapertura de un concurso de persona jurídica en las siguientes situaciones:

1. ${ }^{\circ}$ En caso de existir bienes de la sociedad en poder de un tercero que no pudieron ser localizados a pesar de los intentos de la administración concursal, pero que aparecen después de la conclusión.

$2 .^{\circ} \mathrm{Si}$ un importante deudor insolvente de la sociedad, llega a mejor fortuna y paga el importe de su deuda, de manera voluntaria o forzosa.

${ }^{18}$ YANES, “Comentario al artículo 180...”, op., cit., pág. 2962. 
3. ${ }^{\circ} \mathrm{Si}$ un administrador condenado como responsable subsidiario e inicialmente insolvente deviene en solvente. $\mathrm{O}$, igualmente, si así sucede con un socio que asumió responsabilidad personal.

4. ${ }^{\circ} \mathrm{Si}$ un acreedor que se entera que la sociedad extinguida realizó un acto en fraude de acreedores se dirige contra el beneficiario del acto y le vence en juicio.

Por tanto, de los supuestos referidos se desprende que la incorporación puede ser automática o por virtud del ejercicio de una acción judicial, lo que pone de manifiesto la oportunidad de regular la legitimación activa de los acreedores para defender sus intereses. En este punto, consideramos que sería conveniente regular todo lo relativo a las acciones de reintegración. No encontramos fundamento para afirmar que los actos del deudor perjudiciales para la masa activa previos a la reapertura son inatacables, pero ante la previsión de la LC de extinción de la sociedad en los casos de conclusión del concurso por inexistencia de bienes y derechos del deudor persona jurídica (artículo 178.3 LC), se echa de menos una norma que regule la legitimación en favor de los acreedores, que, además, se encuentran privados de acciones individuales y a los que sólo les queda la opción de la reapertura. Es ésta otra de las lagunas de LC que pone de manifiesto que el legislador no ha sido consciente de las diferencias existentes entre uno y otro supuesto de reapertura. Repárese en que en el caso de conclusión del concurso de persona natural, los acreedores no sólo conservan la posibilidad de ejercitar sus acciones individuales, sino que también pueden solicitar nuevo concurso, que tendrá la consideración de reapertura si se declara dentro de los cinco años siguientes a la conclusión de otro anterior por inexistencia de bienes o derechos. Es por ello que consideramos que la norma debería referirse a la posibilidad de ejercitar la acción rescisoria concursal (supeditada al plazo y requisitos legales), la general y las demás acciones de impugnación (nulidad, anulabilidad, restitutoria, subrogatoria o rescisoria por lesión., artículo 71.1 y 6$)^{19}$, atribuyendo legitimación expresa a los acreedores adaptando a este caso las pautas marcadas en el artículo 72.1 LC del modo siguiente:

Los acreedores deberán solicitar por escrito al Juez del concurso concluido el ejercicio de alguna acción, señalando el acto concreto que se trate de rescindir o impugnar y el fundamento para ello. Si el juez autoriza que se interponga la demanda, por considerarla fundada, los acreedores litigarán a

${ }^{19}$ Una referencia a las acciones que pueden utilizarse, además de la rescisoria concursal, puede verse en ALCOVER GARAU, G., "Comentario al artículo 71 de la LC", en AA.VV., Comentarios a la Legislación Concursal, dirigidos por PULGAR EZQUERRA, ALONSO UREBA, ALONSO LEDESMA Y ALCOVER GARAU,, T. I, Dykinson, Madrid, 2004, págs. 774 y 775 y LEÓN, F., "Comentario del artículo 71 de la LC”, en AA.VV., Comentario de la Ley Concursal, dirigidos por ROJO Y BELTRÁN, Vol. I, Civitas, Madrid, 2004, pág. 1321. 
su costa en interés de la masa, aunque si la demanda fuese total o parcialmente estimada, tendrán derecho a reembolsarse con cargo a la masa activa de los gastos y costas en que hubieren incurrido, hasta el límite de lo obtenido como consecuencia de la sentencia, una vez que ésta sea firme (artículo 72.1 en relación con el 54.4, ambos de la LC). En cuanto al procedimiento, tanto las acciones rescisorias como las demás de impugnación, deberían tramitarse ante el Juez del concurso concluido, al que debería atribuirse competencia expresa para ello, por el cauce del incidente concursal (artículo 72.3 LC).

La legitimación pasiva recaerá sobre quienes hayan sido parte en el acto impugnado. Incluso, si el bien que se pretende reintegrar hubiera sido transmitido a un tercero, la demanda también dirigirse además contra éste, cuando el actor pretenda desvirtuar la presunción de buena fe del adquirente o atacar la irreivindicabilidad de que goce o la protección derivada de la publicidad registral (artículo 72.2 LC).

Respecto a los efectos de la rescisión, debería establecerse que la sentencia que estime la acción declarará la ineficacia del acto impugnado y condenará a la restitución de las prestaciones objeto de aquel, con sus frutos e intereses (artículo 73.1 LC que sigue la línea del 1259.I CC). Sin embargo, como el mecanismo de la rescisión opera a través de la devolución de las prestaciones anteriormente ejecutadas, el texto legal, siguiendo las pautas generales de la LC, debe aclarar que si los bienes y derechos salidos del patrimonio del deudor no pudieran reintegrarse a la masa por pertenecer a tercero no demandado o que, conforme a la sentencia, hubiera procedido de buena fe o gozase de irreivindicabilidad o de protección registral, se condenará a quien hubiera sido parte en el acto rescindido a entregar el valor que tuvieran cuando salieron del patrimonio del deudor concursado, más el interés legal. Si la sentencia apreciase mala fe en quien contrato con el concursado, se le condenará a indemnizar la totalidad de los daños y perjuicios causados a la masa activa (artículo 73.2 LC que sigue lo previsto en el artículo 1259.II CC).

\section{Actualización de la lista de acreedores}

Tratándose de reapertura de concurso de persona jurídica, la extinción de su personalidad por la resolución de conclusión y la no recuperación de acciones por los acreedores, permite deducir que, salvo contadas excepciones (por ejemplo, los créditos en los que el acreedor disfrute de fianza de tercero, que se reconocerán por su importe sin limitación alguna y sin perjuicio de la sustitución del titular del crédito en caso de pago por el fiador: artículo 87.6 LC), coincidirán los acreedores existentes en el momento de la conclusión y de la reapertura.

Una vez determinados los créditos subsistentes, deberá procederse a fijar su cuantía, lo que, fundamentalmente, exigirá la concreción de los intereses devengados (intereses que, con carácter general, tendrán la consideración de 
créditos subordinados: artículo 59.2 LC), sin distinción entre uno y otro modelo de reapertura, al quedar afectados los acreedores de igual modo por la impuntualidad en el pago. Como la suspensión del devengo de intereses despliega su eficacia únicamente a los efectos el concurso ${ }^{20}$, se devengarán desde la fecha de declaración del primer concurso hasta la de la reapertura, en que su devengo queda suspendido (artículo 59.1 LC).

Por su parte, la incorporación de la relación de los acreedores posteriores, presenta interés en el ámbito de la reapertura de concurso de una persona natural, aunque tiene escaso significado ante la reapertura de concurso de persona jurídica, al estar legalmente extinguida.

Dejamos para el final de este apartado la cuestión de si cabe la posibilidad de que los acreedores concursales anteriores a la conclusión que no realizaron la comunicación de sus créditos en el concurso inicial, ni fueron incluidos en la lista de acreedores por no resultar éstos de los libros y documentos del deudor ni constar por cualquier otra razón en el concurso (artículo 86.1 LC), soliciten la inclusión de sus créditos en la nueva lista relativa al procedimiento reabierto. Para el estudio del tema, vamos a tratar por separado las situaciones de conclusión y reapertura del concurso de una persona natural y de una persona jurídica, si bien, con carácter previo, nos parece necesario señalar que la comunicación de créditos en un concurso constituye una carga, en el sentido de actividad dirigida a obtener con más probabilidad la inclusión (dado que ahora no es necesaria en la medida que no es la única vía para obtenerla) en la lista de acreedores y, por tanto, para poder participar en el correspondiente procedimiento concursal:

- En el caso concurso de persona natural, imaginemos un acreedor ordinario que, por la razón que sea, no realiza la comunicación y no es incluido en la lista de acreedores del concurso inicial. En realidad, posiblemente mal asesorado ${ }^{21}$, decide no realizar la comunicación porque ya sabe que sólo van a ser pagados los créditos con privilegio especial. El concurso concluye sin pagar a los acreedores restantes, quedando el deudor quedará responsable del pago de los mismos y recuperando los acreedores la posibilidad de iniciar ejecuciones singulares, en tanto no se acuerde la reapertura del concurso o no se declare nuevo concurso (artículo 178.2 LC). La cuestión que aquí se plantea es si este acreedor podrá reclamar su deuda mediante el ejercicio de acciones individuales. En principio, no vemos impedimento para admitirlo,

\footnotetext{
${ }^{20}$ BELTRÁN Y MARTÍNEZ FLOREZ, “Comentario del artículo 178...”, op. cit., pág. 2665.

${ }^{21}$ A las ventajas otorgadas por la Ley a los acreedores cuyos créditos son reconocidos en el concurso, se refieren BELTRÁN Y MARTÍNEZ FLOREZ, en "Comentario del artículo $178 \ldots$, op. cit., págs. 2660-2661.
} 
siempre que justifique su condición de acreedor y que su derecho no está prescrito ${ }^{22}$. No creemos que la aprobación definitiva de la lista de acreedores prolongue sus efectos más allá del concurso concluido ${ }^{23}$. La otra opción que podría plantearse el acreedor para cobrar su crédito sería instar un procedimiento concursal, un nuevo procedimiento concursal, que tendrá la consideración de reapertura si se cumplen los requisitos previstos en el artículo 179.1 LC. En este caso, tampoco vemos ningún impedimento para que "nuestro acreedor" forme parte de la nueva lista como acreedor instante y, por tanto, como privilegiado general de los del artículo 91.6 LC. Creemos que se trata de un acreedor incorporado a la relación con los "acreedores posteriores" (artículo 180.1 in fine), aunque su crédito (que suponemos que no está prescrito) es anterior al concurso inicial. Es por ello que no consideramos que el Juez deba rechazar de oficio la inclusión del "nuevo acreedor concursal" a la luz de lo previsto en el artículo 180.2 in fine de la LC ("el Juez rechazará de oficio y sin ulterior recurso aquellas pretensiones que no se refieran estrictamente a las cuestiones objeto de actualización").

- Tratándose de concurso de persona jurídica, la cuestión resulta más compleja. Según nuestro parecer, lo justo sería adoptar una solución más o menos similar, atendiendo a las diferencias entre uno y otro supuesto. Ello pasaría por defender que, si concurriesen los presupuestos legales, los acreedores que no realizaron la comunicación de créditos ni fueron reconocidos de otro modo (no los que fueron excluidos por sentencia firme: artículo 196.4 LC, que si están afectados por lo

${ }^{22}$ En principio, a la luz de lo previsto en el artículo 60 LC, y dado que, al igual que los demás acreedores y a pesar de su extraña situación, no recupera la acción individual hasta que concluye el procedimiento concursal, podía pensarse que la prescripción queda interrumpida desde la declaración del concurso. Sin embargo, esta postura es cuestionada por BERMEJO GUTIÉRREZ N. ("La interrupción de la prescripción", en AA. VV., Estudios sobre la Ley Concursal. Libro homenaje a Manuel Olivencia, T. III, Marcial Pons, Madrid, 2005 , pág. 2471 y ss.), que señala que el que los acreedores no puedan pretender el cobro de sus créditos fuera del concurso, no significa que éstos no puedan entenderse manifestados en el mismo a los efectos de interrumpir la prescripción. A su juicio, la interrupción de la prescripción no tiene carácter automático, es decir, no se produce por sí sola en el momento de la declaración del concurso. Considera que para que se produzca es necesario que los acreedores comuniquen su crédito al concurso (la comunicación es equiparable a una demanda, que tiene como efecto la interrupción de la prescripción de los créditos) o que el deudor los haya reconocido cuando forma la oportuna relación de acreedores. Siendo ello así, respecto a este acreedor, "que no ha hecho nada", la declaración de concurso no interrumpiría el plazo de prescripción de su crédito.

${ }^{23}$ Distinto sería el caso del acreedor excluido de la lista del concurso inicial por sentencia firme que ponga fin a los incidentes concursales, en la medida en que produce efectos de cosa juzgada (artículo 196.4 LC) 
previsto en el artículo 180.2 in fine), tendrían la posibilidad de solicitar la reapertura o simplemente de comunicar sus créditos en el procedimiento reabierto (artículo 85 LC). No obstante, está solución suscita muchas dudas, puesto que como la conclusión por inexistencia de activos patrimoniales lleva consigo la extinción de la persona jurídica y de su responsabilidad patrimonial (artículo $178.3 \mathrm{LC}$ ), podría ser que la reapertura tuviese que limitarse a la liquidación del activo sobrevenido entre los acreedores reconocidos como tales antes de su extinción (artículo 179.2 LC).

\section{Publicidad y posible impugnación del inventario o de la lista de acre- edores}

Concluidas las operaciones de actualización del inventario y de la lista de acreedores, la administración concursal ha de presentar el nuevo informe actualizado, cuya publicidad e impugnación se acomodarán a lo dispuesto en el Capítulo IV del Título IV de la LC ${ }^{24}$. Por tanto, la presentación al Juez del informe de la administración concursal y de la documentación complementaria se notificará a quienes se hayan personado en el concurso en el domicilio señalado a los efectos de notificación y se publicará en el Registro Público Concursal y en el tablón de anuncios del Juzgado (artículo 95.2 LC), sin perjuicio de que, además, el Juez pueda acordar, de oficio o a instancia del interesado, cualquier publicidad, complementaria que considere imprescindible, en medios oficiales o privados (artículo 95.3 LC).

Para impugnar el inventario y la lista de acreedores está legitimado cualquier interesado. Sin embargo, la LC distingue, en cuanto al cómputo del plazo, según la parte esté o no personada, estableciendo que las partes personadas podrán impugnar el inventario y la lista de acreedores, dentro del plazo de diez días a contar desde la notificación de la presentación del informe. Para los demás interesados, el plazo de diez días se computará desde la última publicación de las previstas en el artículo 95.2, es decir, en el Registro Publico Concursal y en el tablón de anuncios del Juzgado (artículo 96.1). La impugnación del inventario puede consistir en la solicitud de la inclusión o de la exclusión de bienes o derechos o del aumento o disminución del avalúo de los incluidos (artículo 96.2 LC). La impugnación de la lista de acreedores puede referirse a la inclusión o a la exclusión de créditos, así como a la cuantía o a la clasificación de los reconocidos (artículo 96.3 LC).

${ }^{24}$ Un estudio sobre las novedades introducidas por el RDL 3/2009 en materia de notificación, publicidad e impugnación del inventario y de la lista de acreedores, puede verse en ORELLANA CANO, "Aspectos procesales de la Reforma concursal en el marco del RealDecreto-Ley 3/2009”, RDCP, núm. 11, págs. 148 y ss. 
Transcurrido el plazo de impugnación del inventario y de la lista de acreedores sin que se hubiesen presentado impugnaciones o, presentadas éstas, transcurridos los cinco días siguientes a la notificación de la última sentencia resolutoria de las mismas. Una vez introducidas por la administración concursal las modificaciones que procedan en el inventario, en la lista de acreedores y en la exposición motivada de su informe, y puestos de manifiestos durante quince días en la Secretaría del Juzgado los textos definitivos de esos documentos, junto con una relación actualizada de los créditos contra la masa devengados y pendientes de pago, el Juez dictará la resolución que pone fin a la fase común (artículo 96.4 y 98.1 LC) ${ }^{25}$.

\section{LA SOLUCIÓN LIQUIDATORIA PARA EL CONCURSO REA- BIERTO}

En el caso de las personas jurídicas, la reapertura "se limitará a la fase de liquidación de los bienes y derechos aparecidos con posterioridad (artículo 179.2 LC). Por ello, concluidas las operaciones descritas anteriormente, el Juez acordará, en la propia resolución que pone fin a la fase común, la apertura de oficio de la liquidación, que se regirá por lo previsto en los artículos 148 y ss. de la LC. Concluida ésta, la administración concursal realizará la correspondiente rendición de cuentas de la reapertura, según las previsiones contenidas en el artículo $181 \mathrm{LC}^{26}$.

\section{Bibliografía}

ÁlCALA DIÁZ, M. a A., "Comentario al artículo 176", en PULGAR EZQUERRA/ ALONSO UREBA/ ALONSO LEDESMA/ ALCOVER GARAU, Comentarios a la Legislación Concursal, Tomo II, Dykinson, Madrid, 2004, págs. 1457 y ss.

ALCOVER GARAU, G., "Comentario al artículo 71", en PULGAR EZQUERRA/ ALONSO UREBA/ ALONSO LEDESMA/ ALCOVER GARAU, Comentarios a la Legislación Concursal, Tomo I, Madrid, Dykinson, 2004, págs. 767 y ss.

${ }^{25}$ Con la reforma se ha añadido un párrafo $2 .^{\circ}$ al artículo 98 , para establecer que está resolución será apelable y tendrá la consideración de apelación más próxima a los solos efectos de reproducir las cuestiones planteadas en los recursos de reposición o incidentes concursales durante la fase común a que se refiere el artículo 197.3 LC. Sobre la cuestión, ORELLANA, “Aspectos...”, op. cit., págs. 150-151.

${ }^{26}$ Sobre la formulación de la rendición de cuentas, PÉREZ MILLÁN, D., " Comentario al artículo 181 de la LC”, en AA.VV., Comentarios a la Legislación Concursal, dirigidos por PULGAR EZQUERRA, ALONSO UREBA, ALONSO LEDESMA Y ALCOVER GARAU,, T. II, Dykinson, Madrid, 2004, págs. 1506 y ss. 
ALONSO ESPINOSA F. J., "Comentario a los artículos 179 y 180", en PULGAR EZQUERRA/ ALONSO UREBA/ ALONSO LEDESMA/ ALCOVER GARAU, Comentarios a la Legislación Concursal, Tomo II, Dykinson, Madrid, 2004, págs. 1491 y ss.

ALONSO LEDESMA, C., "Delimitación de la masa pasiva: las clases de créditos y su graduación, en GARCÍA VILLAVERDE, R./ALONSO UREBA,A./PULGAR EZQUERRA, J. (Dirs), Derecho Concursal. Estudio sistemático de la Ley 22/2003 y de la Ley 8/2003 para la reforma concursal, Madrid, 2003, págs. 363 y ss.

ALONSO UREBA, A.,"El artículo 48.2 LC y el marco de las relaciones de responsabilidad concursal del artículo 172.3 con la responsabilidad de los auditores y con las acciones societarias e responsabilidad de administradores y liquidadores", RDCYP, núm. 1, págs. 91 y ss.

ARENA, A., La riapertura del fallimento (Il falimento del fallito), Milán, 1938.

— Introduzione allo Studio del diritto commerciale. Fallimento e procedure concorsuali, Milán, 1957.

ATIENZA LÓPEZ, J., "Reapertura del concurso por incumplimiento de convenio: los créditos nacidos durante la vigencia del convenio son créditos concursales y no contra la masa", Revista Ceflegal, Núm. 48/2009, págs. 11 y ss.

BELTRÁN E./ MARTINEZ FLOREZ A., "Comentario al artículo 178”, en ROJO/BELTRÁN, Comentario de la Ley Concursal, Tomo II, Madrid 2004, págs. 2642 y ss.

BELLIDO, R., "Comentario a los artículos 176, 179 y 180”, en ROJO-BELTRÁN, Comentario de la Ley Concursal, Tomo II, Madrid, 2004, págs. 2617 y ss.

BERMEJO GUTIÉRREZ N, "La interrupción de la prescripción”, en AA. VV., Estudios sobre la Ley Concursal. Libro homenaje a Manuel Olivencia, T. III, Marcial Pons, Madrid, 2005, págs. 2471 y ss.

COLINO MEDIAVILLA, J. L.," La publicidad del concurso en virtud del Real Decreto-Ley 3/2009", en RDCP, núm. 11, 2009, págs. 123 y ss.

GADEA, E., Iniciación al estudio del Derecho Concursal, 2. ${ }^{\mathrm{a}}$ Ed., Dykinson, Madrid, 2010.

GONZÁLEZ OLLEROS, J: “Comentario al artículo 179”, en Derecho Concursal Práctico (Comentarios a la Nueva Ley Concursal), Coord. por Fernández-Ballesteros, La Ley/Iurgium, Madrid, 2004, págs. 806 y ss.

GONZÁLEZ GOZALO, A., "Comentario al artículo 176", Comentarios a la Ley Concursal, BERCOVITZ RODRÍGUEZ-CANO, R (Coord.), Tecnos, Madrid, 2004, págs. 1826 y ss.

GUTIERREZ GILSANZ, A., "Conclusión y reapertura del concurso", en AA. VV., Aspectos jurídicos del concurso de acreedores (II), Ed ICAM, 2004, págs. 321 y ss. 
- "La tramitación ordinaria del convenio en la reforma de la Ley Concursal contenida en el Real Decreto-Ley 3/2009”, en RDCP, núm. 11, 2009, págs. 99 y ss.

LEON SANZ, F., "Comentario al artículo 71", en ROJO/BELTRÁN, Comentario de la Ley Concursal, Tomo I, Madrid, 2004, págs. 1301 y ss. ORELLANA CANO, N., "Aspectos procesales de la reforma concursal en el marco del Real Decreto-Ley 3/2009”, RDCP, núm. 11, págs. 143 y ss.

PÉREZ MILLÁN, D., "Comentario al artículo 181", en PULGAR EZQUERRA/ ALONSO UREBA/ ALONSO LEDESMA/ ALCOVER GARAU, Comentarios a la Legislación Concursal, Tomo II,, Dykinson, Madrid, 2004, págs. 1506 y ss.

PROVINCIALI, R, Trattato di diritto fallimentare, T. III, Milano, 1974.

PROVINCIALI R./ RAGUSA MAGIORE, Instituzioni di Diritto Fallimentare, Ed. CEDAM, Milán, 1988, págs. 624 y ss.

PULGAR EZQUERRA, J., "El presupuesto objetivo de la apertura del concurso de acreedores", en AA. VV., Derecho Concursal, Estudio sistemático de la Ley 22/2003 y de la Ley 8/2003, para la reforma concursal, dirigido por García Villaverde, Alonso Ureba, Pulgar Ezquerra, Dilex, Madrid, 2003, págs. 55 y ss.

- La declaración del concurso de acreedores, Ed La Ley/Ramón y Cajal, Madrid, 2005.

- La cancelación registral de las sociedades de capital, McGraw-Hill, Madrid, 1998.

RAMÍREZ, J. A., La quiebra. Derecho concusal español, Tomo III, Barcelona, Ed. Bosch, 1959.

ROJO, A "La reforma del derecho concursal español, en ROJO, A., (Dir.), La reforma de la legislación concursal, Madrid, Marcial Pons, 2003, págs. 87 y ss

- "Comentario al artículo 2", en ROJO-BELTRÁN, Comentario de la Ley Concursal, Madrid, 2004, Tomo I, págs. 164 y ss.

SÁNCHEZ CALERO, J., "La reforma de la propuesta anticipada de convenio", en RDCP, núm. 11, 2009, págs. 85 y ss.

SEQUEIRA MARTIN, A, "Comentario al artículo 23", en PULGAR EZQUERRA/ ALONSO UREBA/ ALONSO LEDESMA/ ALCOVER GARAU, Comentarios a la Legislación Concursal, Tomo I, Dykinson, Madrid, 2004, págs. 485 y ss.

YANES YANES, P., "La reapertura de la quiebra", Ed Lex Nova, Valladolid, 1992.

— "Comentario a los artículos 176, 179 y 189 LC", en SÁNCHEZ-CALERO, J./GUILARTE GUTIÉRREZ, V., Comentarios a la legislación concursal, T. III, Lex Nova, Valladolid, 2004, págs. 2905 y ss. 